\title{
VRYHEID EN GEBONDENHEID IN DIE KUNS
}

Die vraagstuk van vryheid en gebondenheid in die kuns staan, nie alleen in ons land nie, op die oomblik in die sentrum van die belangstelling. Dis 'n onderwerp wat baie aspekte het. Daarom is dit nodig dat ek vooraf my terrein bepaal. Ek stel my voor, en ek meen ook dat dit van my verwag word, om dit suiwer prinsipieel te benader. D.w.s. ek sal nie ingaan op die uiters belangrike praktiese aspek van die beleid wat ons moet volg - en die probleme wat dit meebring nie - waar leiding gegee moet word aan die opgroeiende jeug en aan almal wat nie die geestesrypheid besit om 'n kunswerk suiwer esteties te beoordeel nie. Vir daardie taak, waarvoor elkeen van ons in een of ander samelewingsverband of -verhouding te staan kom, is 'n duidelike prinsipiële insig in die wese van kuns, sy vryheid en sy gebondenheid, gebiedende voorvereiste.

Ook sal ek my moet bepaal tot enkele kernaspekte, wat ek in die kort tydjie tot my beskikking slegs heel in die algemeen sal kan aanroer.

Graag erken ek dat ek 'n dankbare gebruik maak van Dooijeweerd se grondgedagte van die wetskringe en hulle verbande, al is ek as non-filosoof nie suiwer wysgerig in my terminologie nie.

Laat ek begin met te sê dat die woorde vryheid en gebondenheid vir my primêr nie 'n teenstelling oproep nie. Dié begrippe is vir my eerder twee aspekte van dieselfde saak. Gebondenheid beteken hier vir my nie onderworpe wees aan van buite-af opgelegde wette nie, dit beteken funksioneer volgens, getrou wees aan, eie, diepste wese. Dat ons ook op kunsgebied praat van die probléém van vryheid en gebondenheid, dus wél van 'n teenstelling uitgaan, is die gevolg van die sonde, waardeur die volmaakte funksionering op alle terreine van die lewe, fisies en psigies, dus ook in die domein van skoonheidskepping en -genieting, verstoor is.

In die paradys het die mens die opdrag ontvang om oor die skepping te heers; ook moes hy aan elke dier 'n naam gee, d.w.s. hy moes die skepping interpreteer - ek neem aan met al sy vermoëns, dus ook esteties. Hy was dus nie alleen die kroon van die skepping nie, hy was ook orgaan daarvan, hy moes dit voortset. In die staat van regverdigheid 
het dié taak van die mens beteken volkome verwesenliking van al die vermoëns wat hy ontvang het, konflikloos en tot verheerliking van sy Skepper. Ná die sondeval het hy spranke van die gawe en ook die taak behou om oor die skepping te heers en dit te interpreteer. Maar hoewel dit hom tot groot troos is, het dit geword ' $n$ smartlike worsteling om die geskonde beeld te herstel, 'n hunkering na die verlore paradys, nie meer 'n heilige heenreike nie maar 'n smartlike verlange na die toekomstige heilstaat. Hy het sy naaktheid ontdek, bewus geword van homself, hyself staan as objek in die middelpunt van sy kuns - die grootste bron van smart en innerlike botsing. Sodat dit in ons bedeling tot die wese van die kuns behoort dat dit uit konflik gebore is.

Daardie heerlike vryheid om met sy fantasie te heers oor, herskeppend te speel met die ganse skepping in sy oneindige fisiese en psigiese verskeidenheid, hou nou groot gevare in. Nie alleen in die laboratorium nie, ook in die kuns kan verkeerde hantering die gegewenhede waarmee die mens werk, tot gevaarlike plofstowwe maak. Want met sy deur die sonde verduisterde gees funksioneer die mens in die vervulling van sy estetiese taak nie meer suiwer volgens die ordinansies van God nie, kom hy daarmee in botsing. Sodat daar by sowel die kunsskepper as die kunsgenieter onsuiwerheid van opvatting en praktyk bestaan en daar ook tussen die twee dikwels misverstand, verbittering, stryd heers.

Die groot massa - en dit geld van alle tye en alle volke verlang, bewus of onbewus, van 'n kunswerk dat dit in diens moet staan van godsdienstige, sedelike, politieke e.a. ideale. Die kunstenaar antwoord hierop dikwels hooghartig met die slagspreuk van die Franse romantici: „l'art pour l'art", wat in die praktyk al te dikwels beteken "l'art pour l'artiste" en ook ' $n$ ' ontkenning van enige verband tussen kuns en godsdiens of sedelikheid. Ons het hiermee gekom by die een kernprobleem waarby ek met $\mathrm{u}$ wil stilstaan.

"L'art pour l'art" is vir my waar in dié sin dat die kuns behoort tot die kring van die skoonheid en primêr onderhewig is aan die wet van die skoonheid, wat anders is as, maar nie 'n ontkenning is van, dié van die ander kringe soos bv. die godsdienstige, die sedelike, die logiese. Wat sou daar bv. oorbly van die skoonheid van 'n sprokie, waarin diere soos mense handel en praat en natuurverskynsels as persoonlike wesens 
optree, as dit beoordeel moes word volgens dic wette van die suiwere logika?

Natuurlik staan dit elkeen vry om 'n boek, 'n beeldhouwerk, 'n skildery te beoordeel na die godsdienstige, sedelike, politieke of ander „boodskap" wat hy daarin soek of meen te vind. Mits hy dan maar besef dat hy daarmee besig is om die kunswerk uit sy sfeer te ruk, dit te beoordeel volgens buiteestetiese norme, nie volgens dié eienskappe wat dit tot kunswerk maak nie. Hy doen dan soos die Transvaalse beesboer wie se enigste kommentaar op die beroemde skildery "De Stier" van Paulus Potter in die Mauritshuis, Den Haag, was dat hy daardie bul sowaar nie onder sy beeste wou hê nie! Vir die skildery as kunswerk, vir die monumentale silhoeëttering van die forse dier teen die fyn geskilderde lug het hy geen oog gehad nie. Hy was op soek na 'n stamboekbul.

Dit wil nie sê dat die skoonheidskring geïsoleer is van die ander kringe, dat 'n werk van skoonheid in 'n yle, onwesenlike sfeer sweef nie. Die kunstenaar vind die prikkel tot estetiese skeppingsdrif, die boustof vir die verbeelding, op die terrein van die ganse lewe. Hy is volledig mens; hy is in al die lewenskringe werksaam. Selfs die mees radikaal-abstrakte skildery, wat alle heenwysing na die herkenbare werklikheid prysgegee het, het ontstaan uit religieuse, etiese of ander konflikte en spreek tot ons ook in daardie kringe, sy dit dan nie eksplisiet nie. Meer nog: die wette van al die ander kringe is óók geldig in 'n werk wat in die skoonheidskring leef, maar: anders, want onder leiding van, "gekwalifiseer" deur die estetiese wet.

Om terug te keer tot die sprokie. Daarin gebeur allerlei dinge wat in die nugtere werklikheid nie moontlik is nie maar wel in die skoonheidskring met sy vryheid van fantasie. Dit beteken egter nie dat 'n sprokie allerlei willekeurighede kan bevat nie. Hierdie kunssoort gehoorsaam aan sy eie logika die logiese wet onder leiding van die estetiese.

Ek het opsetlik dié kinderlike kunssoort as voorbeeld gekies, want in wese is elke kunswerk 'n sprokie, die gewone werklikheid deur verbeeldingskrag omgeskep tot 'n nuwe, geestelike werklikheid wat, gehoorsaam aan sy eie, estetiese wet, die kunstenaar se ontdekte waarheid as skoonheid openbaar.

In die estetiese kring is dus ook werksaam die wette van al die ander kringe, bv. die religieuse, die etiese, die logiese, 
die ekonomiese, maar onder leiding van die estetiese, daarmee geïntegreer. M.a.w. dic estetiese oordeel is nie 'n afsonderlike oordeel, los van of selfs in konflik, met die ander nie. Ons kan tog nie sê nie: „hierdie gedig is voortreflike kuns; net jammer dat die digter sy taal nie ekonomies aanwend nie hy gebruik te veel woorde". Dis immer juis die wyse waarop gehoorsaam word aan die ekonomiese wet, wat in die vormgewing van kardinale belang is; dít bepaal die estetiese vermoë van die digter, die gehalte van sy werk.

Dieselfde geld vir die rol wat die religieuse en die etiese in die skoonheidskring speel. Ons kan nie 'n werk as kunswerk hoogskat maar dit veroordeel om sy godsdienstige of sedelike ,inhoud" nie. Dan huldig ons maar weer die ou meganistiese skeiding van inhoud en vorm, die vorm as statiese ding, die fyn kristalvaas waarin die inhoud "gegiet" word, of soos Da Costa dit met die volgende beeld gestel het: „de bij, die haar zeshoek van was niet bouwt om de schoone regelmatige figuur zelve, maar om de eetbare honig, die het hare bestemming is daarin neer te leggen".

Inhoud en vorm, as ons dan móét onderskei - nie skei nie! - is slegs twee aspekte van dieselfde saak. Die vorm is 'n dinamiese beginsel. Ons sou met net so veel reg kan sê dat die vorm die inhoud skep as die teenoorgestelde.

'n Werk wat wesenlik godslasterlik is, op leuen berus, eties voos is, kán nie kuns wees nie. U kan dit ook omdraai: 'n kunswerk kán nie godslasterlik of leuenagtig of onsedelik wees nie. Daar waar hy dit wél is, is hy nie kuns nie.

Staan my toe om dit nader toe te lig.

Ons lewe in 'n wêreld wat fisies en geestelik verdorwe is deur die sonde. Dáárin moet die kunstenaar die waarheid vind en verbeeld. Dit kan hy alleen doen as hy dié sondewerklikheid as feit aanvaar en uitbeeld, nie as hy dit soetlik verdoesel nie - dan sou hy hom blootstel aan die kritiek van 'n geestige Fransman wat gesê het dat die Katolieke kuns van die 19e eeu op die vraag van Jesus: ,as die sout souteloos geword het, waarmee sal julle dit smaaklik maak?" geantwoord het: met suiker! Dis hierdie verdoeseling en oppervlakkige, nie aan die lewe ontworstelde „optimisme" wat die Franse naturaliste uitgelok het tot die slagkreet: le beau c'est le laid die skone, dis die lelike.

Een van die gevoeligste digter's wat ek ken, J. H. Leopold, 
het hierdie wesenstrek van die kuns om ook in die afstootlike die waarheid, die skone te vind, verbeeld in die volgende gedig:

Jezus, die door de wereld ging, was in een landstad aangekomen

en had zijn ongemerkten weg over het marktplein heen genomen.

En zag een hond stroef als een wolf plat op de steenen, onbewogen,

wiens leven heengeweken was, wiens Jozef uit de put getogen.

En een: de walg van dit gezicht benevelt en verwart het hoofd

met troebelingen als een kaars roetwalmend door de wind gedoofd.

Een ander: van dit gistend vod en vuil het eenigste gewin

is duisternissen voor het oog en schrik en afschuw voor den zin.

Zoo zong een ieder daar zijn lied maar allen in denzelfden toon

en overstelpten met verwijt en spraken bitterheid en hoon.

Jezus zag naar het liggend dier en sprak en zeide enkel dit

en was beschamende rondom: de tanden zijn als paarlen wit.

Ons kan nou maar eenmaal die lig die helderste sien in teenstelling tot die duisternis, en glad nie alle kuns is soos Mei in Gorter se sprokie "louter niets dan lieflijkheid" nie. Inteendeel, kuns is dikwels skokkend, dit kan selfs verskriklik wees, tot die harmonie van die musikale komposisie dra soms ook ontstellende dissonante by. Wat nie wil sê dat werk wat bly vassteek in die duisternis, nie uitreik na die lig nie, hoë kuns kan wees nie. Nog minder dat uitbeelding van die sonde uit blote verlustiging daarin hoegenaamd kuns is.

Die kunstenaar is die rustelose soeker na die essensiële, die waarheid. Hy is voortdurend in opstand teen die onegte, die skyn, wat hy veral ook vind in verstarring van die gees wat hom verberg agter konvensionele vormediens. Hy skud 
sy tydgenote gedurig op ruwe wyse wakker uit hulle geestelike traagheid, ontneem hulle daarmee dierbare illusies. Daarom is ons so maklik geneig om hom te sien as die ontkenner van religieuse en etiese waardes, teruyl hy in werklikheid die hartstogtelike verdediger daarvan is, slegs die tempeltjies en afgodjies wat ons vir ons opgerig het, onderstebo skop.

Die kunstenaar gee sy godsdienstige, sedelike, politieke e.a. oortuiginge nie soos die pedagoog, die predikant, die volksleier dit gee, eksplisiet in die vorm van 'n uitdruklike waarskuwing of moralisering nie. Hy preek nie, moraliseer nie, hy verbeeld. Hy laat sy verhaal, sy figure, sy voorstellinge en fantasieë vir hulle self spreek. Dikwels lyk dit of hy onbewoë, neutraal langs sy skildery staan, nie veroordeel, nie verdedig nie. Maar wie met onderskeid, d.w.s. esteties, lees, luister, kyk, sal in die werk tog 'n duidelike konkretisering van 'n lewensbeskouing, 'n strekking ontdek.

Ek vertrou dat u, op grond van my betoog tot dusver, sal saamstem dat die begrippe vryheid en gebondenheid nie alleen geld vir die kunstenaar nie maar ook vir die kunsbeskouer, die kritikus. Alleen as ons 'n kunswerk onbevange nader, ons na die beste van ons vermoë ingespan het om dit te beléwe, kan ons in staat wees om te oordeel of wat andersins godsdienstig of sedelik aanstootlik kan wees, deur die estetiese kwalifikasie van die religieuse of etiese wette verantwoord is, of daardie vloek, daardie uitbeelding van onsedelikheid gegee is uit blote verlustiging ò onverskilligheid òf omdat dit funksioneel noodsaaklik was vir 'n lewensware beeld.

Kunsgenieting is 'n Godgegewe gawe wat ook 'n roeping meebring, 'n gebondenheid om dit te ontgin deur aktiewe werksaamheid van die gees. Dis nie slegs 'n passiewe ondergaan van sinnestreling, 'n swelg in sentiment nie. Die moeilikste deel van dié ontginningstaak is seker wel dat ons moet leer om nie 'n kunswerk te nader met allerlei vooropgestelde menings nie, om te besef dat die aanwesigheid van skoonheid nie afhanklik is van ooreenstemming met ons lewensbeskouing nie. Ek haal hier 'n baie sterk uitspraak van Abraham Kuyper aan: „De wereld van het Schoone is een zelfstandige wereld, die zich aan geen belijdenis binden laat, op zichzelf voortleeft en verder voortschrijdt, en wel de kracht van het Evangelie in de vrijmaking van den geest in zich opneemt, maar zonder daarom als zoodanig zich aan de belijdenis van het Evangelie te binden". 
Dit gee ons dic vryheid én die gebondenheid om die skoonheid, dic waarheidsmomente, te waardeer in die kuns van die heidense Grieke, in die kommunistiese verse van 'n Henriëtte Roland Holst of ' $n$ Gorter, in die jonger en jongste Afrikaanse poësie ook waar dit so ver afgewyk het van die ortodoks Christelik godsdienstige opvattinge, selfs in die skepsis van 'n Voltaire of 'n Menno ter Braak.

Dit wil nie sê nie dat ons nie ook 'n kunswerk in laaste instansie as lewenswaarde meet teen die steeds aanwesige ag. tergrond van ons lewens- en wêreld- en Godsbeskouing nie.

Om dus die eerste deel van my bespreking kort saam te vat:

Kuns behoort tot die kring van die skoonheid en gehoorsaam aan die wet van daardie kring.

In die skoonheidskring is ook werksaam die wette van ander kringe maar onder leiding van die skoonheidswet.

Die kuns is nie dienares van die godsdiens of die sedelikheid nie maar gehoorsaam op estetiese wyse aan die reli gieuse en etiese wette.

Die beginsel van vryheid en gebondenheid geld nie alleen vir die kunsskepper nie maar ook vir die kunsbeskouer.

Die leiding en beskerming van wie nie die geestelike rypheid van estetiese onderskeiding besit nie, is 'n uiters verantwoordelike taak waarvoor nie alleen pedagogiese en sosiologiese insig nodig is nie maar ook insig in die wese van kuns.

Ek het terloops verwys na die kardinale belang van die vormgewing en wil na aanleiding daarvan kortliks stil staan by ' $n$ tweede duidelike openbaring van die beginsel vryheidgebondenheid in die kuns.

Mens sou kuns o.a. kan karakteriseer deur te sê dat dit sinlike gestalte aan of suggestie van die bo-sinlike gee. Daarvoor bied die onderskeie kunste onderskeie media wat tot verskillende sintuie of op verskillende wyse tot die sinne spreek. Dit gee aan die kunstenaar as 't ware die vryheid om sy spel te dryf met die verskillende vorme en hulle moontlikhede. Maar dié vryheid is ook weer gebonde aan die eie aard van die kunssoort of -medium, aan die begrensde moontlikhede daarvan en aan dié van die kunstenaar se eie aanleg.

Wel besit die medium van die een kuns die vermoë om assosiasies op te roep met dié van ander kunste. Die fresko's van Michelangelo vertoon bv. 'n sterk skulpturale karakter en gee die indruk dat hy net soos in sy beeldhouwerk elementale 
figure in die ruimte skep. Ghiberti se reliefs vertoon 'n sterk (te sterk!) skilderkunstige trek; in sommige gedigte van Slauerhoff is dit asof hy die een groue rotsblok op die ander stawel, terwyl die vroeëre poësie van J. C. Bloem dikwels aandoen as tjellomusiek. Die Vlaminge praat graag van hulle singende torings, waarby hulle seker nie alleen aan die galm van die beiaard dink nie.

Ons het hier ook te doen met die subtiele verskynsel van sinestese, die stimulering van een sintuig deur die indruk van 'n ander - ons hoor kleure en sien of voel geluide. Luister slegs na die subtiele verse van Baudelaire:

Il est des parfums frais comme des chairs d'enfants, Doux comme des hautbois, verts comme des prairies.

(Daar is geure wat koel is soos kinderlyfies, soet soos hobo's, groen soos grasvelde).

Veral die impressioniste was besonder ontvanklik daarvoor en het die taal verryk met tal van sinestetiese beelde. Ons praat van dawerende rooi, sketterende geel, sonore goud, van donsige stilte.

Tog bly elke kuns beperk tot die moontlikhede van sy eie medium, en Carlyle se uitspraak dat ,architecture is frozen music" is hoogstens suggestiewe beeld.

Laat ek dit toelig met die taalkuns as voorbeeld. Die digter of prosaskrywer se medium is die woord, wat betekenisdraer is maar in die ritmies-akoestiese verband van sin en vers die vermoë besit om gehoors-, gesigs- of tasindrukke op te roep en 'n rykdom van subtiele assosiasies daarmee. Vanaf Homeros tot die moderne eksperimentele poësie het digters en skrywers hiervan bewus of onbewus gebruik gemaak, maar dit het ook gelei tot oorskryding van die natuurlike grense, soms met noodlottige gevolge.

As Goethe sê „Künstler rede nicht, bilde nur", beklemtoon hy tereg dat die kunstenaar nie die taal bloot verstandelik betogend of beskrywend moet aanwend nie maar gebruik moet maak van die sinlik-evokatiewe krag daarvan. Maar as Horatius sê ,ut pictura poesis" - „poësie is soos 'n skildery", dan lei hy die digkuns op 'n dwaalspoor. Die letterkundige kunswerk besit 'n beeldende vermoë wat jou aan 'n skildery kan laat dink, dit kan nie self 'n skildery wees nie. Ek haal 'n stukkie aan uit die jeugroman van Lodewyk van Deyssel, 
die skrywer wat die impressionistiese strewe na woordskildering tot die uiterste gedryf het:

„Mathilde zette klaar: den broodbak in het midden van de tafel met een lankwerpig (sic!) versch brood, met aan den eenen kant een laag paperig kruim, dat in een koker van korst was geborgen. Het hellende dak der korst, van boven, was donker zwart bruin en ging, bij het zijwaarts afdalen van de korst, in een melkchocolade-kleurig bruin over, van daar in lichter bruin, geel bruin, en de onderkant was grijsig geel, zwart doorschemerend. Aan die éénen uithoek was ook weer het kruim zichtbaar, de andere was een geel bruinig rontetje, als de kin van een Indische vrouw..."

Nadat jy met nogal heelwat inspanning probeer visualiseer het wat Van Deyssel hier wou skilder, kom jy tot die gevolgtrekking dat as die skrywer met penseel en palet kon gewerk het, hy waarskynlik 'n fyn stukkie stillewe sou kon gelewer het. As woordkuns het dit 'n dorre, minisieus opsommende beskrywing gebly wat geen totaalbeeld oproep nie en slegs een trekkie fantasie bevat.

Die eeue deur het digters en skrywers die groot musikale uitbeeldings- en suggestievermoë van die taal besef. Hulle het hulle verse, hulle prosa laat klink soos swaar orrelmusiek, soos die waterklare geluid van 'n fluit in die nag, soos wenende vioolsnare, soos kraaigekras, en dit is die ontginning van die musikaal-ritmiese eienskappe wat die taal in hulle kuns aktiveer tot die oproep van 'n tweede werklikheid, dit 'n derde dimensie gee, soos dit teenswoordig heet. Een van die suiwerste liriese digters, die Franse simbolis Paul Verlaine, eis in sy gedig „Art Poétique": ,voor alles musiek, nogmaals en altyd musiek ... en die res is sommer literatuur!"

Dis een van die boeiendste studies om na te gaan wat die taal deur die samewerking van sy semantiese en musikaalritmiese eienskappe kan doen in 'n gedig. Dis die verdienste van die stillistiek dat dit hiervan so 'n uitvoerige en insiggewende studie gemaak het.

Natuurlik hou te bewuste aanwending van hierdie moontlikhede vir minder hewig voelende, minder oorspronklike digters die gevaar in dat hulle "styl" as afsonderlike doel op homself gaan beoefen; die swakkes word verlei tot oratoriese woordgebruik wat retoriek word, of tot sinledige spel met klanke soos by ons bv. H. H. Joubert, wat die Vryheidslied van die Trekkers soos volg ,besing": 
Uit die tente bruis gesang

met 'n duislend

grief-vergruislend

klankgedrang.

Maar daar is ook die geval van 'n groot digter soos Herman Gorter wat in sy "Mei" sê dat die sielelewe onverdeeldbaar is, dat die musiek die naaste aan die verbeeldingsmoontlikheid daarvan kom, en wat daarna 'n tyd lank sy hewige gewaarwordinge wil verbeeld in verse wat hoofsaaklik klank-ritmies wil wees. Hy skep wondere van sprankelende lig en klank en dansende ritme, maar in verse soos die volgende bereik hy die grense van die poësie:

En de bestraalde ochtendzee -

de zee, de zee, de stormzee, zeë̈, siszée, grijnszée, stormschuim, huilschuim, bruischzée, heetzée, koelzée, hoogzée,

in de ronde, verronde horizonnen -

in de morgenzon, de luchtzon, de witzon, het dag, het witdag.

Teenoor Gorter se sensitivisme, poging tot vergeesteliking van die impressionisme, staan die ekspressionisme wat in sy uiterste konsekwensie terugkeer tot die poësie as oerkreet, die klank, sonder verband met die sinryke woord, wil aanwend tot hiperindividualistiese ekspressiemiddel en dan kom tot die volslae chaos van 'n "gedig" soos die volgende van die dadaïs Kurt Schwitters:

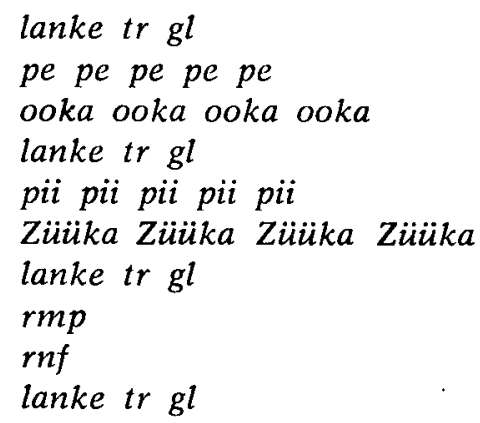

$\mathrm{U}$ sien waartoe dit kan lei as die kunstenaar nie meer die gebondenheid erken aan wette wat voortvloei uit die wese van die kuns nie. Poësie is nie slegs klanke nie, dis 
sinryke woorde in 'n akoesties-ritmies suggestiewe semantiese verband.

Maar ook hier geld vryheid en gebondenheid nie alleen vir die kunstenaar nie maar ook vir die kunsbeskouer, die kritikus.

Dit behoort tot die wese van die kunstenaar, dis 'n onontkombare noodwendigheid dat hy vir die verbeelding van wat byna onverbeeldbaar is, sy uitdrukkingsmiddele tot die uiterste span, gedurig nuwe moontlikhede van sy medium sal ontgin. Anders sou die kuns verval in 'n eindelose herhaling van wat vroeër reeds gesê is, sou dit word 'n giet van nuwe wyn in ou leersakke - en die Bybel vertel ons wat dan gebeur.

Daarom is dit ons plig om voor ons oor ontstellende nuwe vorme ewe gemaklik 'n verdoemende oordeel uitspreek, die nuwe kuns vanuit sy oorspronge te belééf. Wie dit doen, sal van veel moderne kuns bevind dat dit in magtelose eksperiment bly vassteek, veel is nie meer as jag op oorspronklikheid nie, modesug, maar veel sal vir die ernstige bestudeerder ' $n$ eie skoonheid ontsluit en bevat die kieme van nuwe ontwikkeling. Ook die twee laaste sitate wat ek aan u voorgelees het, is nie so bloot koddig as wat dit by die eerste aanhoor vir u mag geklink het nie. Daar sit meer ernstige strewe en meer vormgevoel in as wat die laggers besef, en hierdie werk het nie verbygegaan sonder om stukragte te wees vir nuwe groei nie.

Potchefstroom.

G. Dekker. 